\title{
DESCRIÇÃO ALIMENTAR E ESTÁGIO DE MATURAÇÃO DE CRASSOSTREA BRASILIANA COMERCIALIZADAS NO MERCADO MUNICIPAL DE PARANAGUÁ, PARANÁ, BRASIL
}

\author{
CHRISTO, S. W..$^{*} ;$ IVACHUK, C. S. ${ }^{2} ;$ VERONESE, F. C. ${ }^{2}$; \\ FERREIRA-JR, A. L. ${ }^{3} \&$ ABSHER, T. M. ${ }^{3}$
}

\author{
1. Departamento de Biologia Geral, Universidade Estadual de Ponta Grossa, Ponta Grossa, PR. \\ 2. Universidade Estadual de Ponta Grossa - Bacharelado em Ciências Biológicas, PR \\ 3. Centro de Estudos do Mar, Universidade Federal do Paraná, Pontal do Paraná, PR. \\ ${ }^{*}$ Corresponding author: swchristo@hotmail.com
}

\begin{abstract}
CHRISTO, S. W.; IVACHUK, C. S.2; VERONESE, F. C.;FERREIRA-JR, A. L. \& ABSHER, T. M. Descrição alimentar e estágio de maturação de Crassostrea brasiliana comercializadas no Mercado Municipal de Paranaguá, Paraná, Brasil. Braz. J. Aquat. Sci. Technol. 19(2). elSSN 1983-9057. DOI: 10.14210/bjast.v19n2. Crassostrea brasiliana (Lamark, 1819) is an epibiont filter feeder bivalve. Its fast growth and fast gonadal recovery depend on the amount and quality of the food ingested by the animal, mainly composed of phytoplankton cells. In the coast of Paraná State, Brazil, several aquaculture farms of $C$. brasiliana can be found along the Paranaguá Estuarine Complex (PEC) and Guaratuba Bay. Therefore, this work had as objectives to evaluate the taxonomic composition and cell size of the microalgae ingested by adults of the oyster $C$. brasiliana and to describe its reproductive characteristics (index of meat revenue and stages of gonadal maturation). Oysters cultivated in the PEC were acquired monthly from the Municipal Market of Paranaguá. The oysters $(n=30)$ were then measured and shell length values $(S L)$, height $(S H)$ and gross weight $(G W)$ obtained. Gonadal maturation stages were evaluated through the macroscopic examination of the gonads and revenue index $(R)$ through the wet weight of meat. The digestive gland was removed for the microscopic analysis of the stomach content (i.e. identification and measurement of the microalgae). The highest mean $R$ value $(12.79 \%$ ) was observed in July 2007 , when a great portion of the population presented full gonads, although the predominance of individuals with full gonads (partially full and full) occurred in periods of warmer waters. The genera found in the digestive tract were: Nitzchia, Gyrosigma, Navicula, Pleurosigma, Thalassionema, Frustulia, Anomoeoneis, Chroococcus, Cocconeis, Diploneis, Cyclotella, Coscinodiscus and Prorocentrum, with the cell size varying from 5 to $260 \mu \mathrm{m}$.
\end{abstract}

Keywords: Oyster, Microalgae, Reproduction, Stomach content.

\section{INTRODUÇÃO}

O termo aquicultura faz referência a todas as atividades cujo objetivo é o desenvolvimento, crescimento e comercialização de organismos aquáticos, sejam eles cultivados em água doce, salobra ou salgada (Pillay \& Kutt, 2005). Em termos mundiais, a aquicultura vem crescendo, tornando-se assim um setor importante na produção de alimentos altamente proteicos. A produção global relatada de peixes e outros animais marinhos alcançou 90,43 milhões de toneladas em 2012, tendo os moluscos uma produção de $22,8 \%$ (FAO, 2014). Os ambientes estuarinos, considerados os ecossistemas mais produtivos das regiões costeiras, pela capacidade de armazenamento e produção de nutrientes, constituem áreas de grande potencial para o desenvolvimento de atividades de maricultura, onde se destaca a ostreicultura (Mann, 1992).

Entre as espécies que constituem a família Ostreidae, as ostras do gênero Crassostrea Sacco, 1911 são consideradas como uma importante fonte de renda para as comunidades das regiões costeiras do litoral brasileiro. Devido ao seu alto valor alimentício, ao potencial uso da concha como matéria prima na fabricação de produtos medicinais e à facilidade de cultivo, a ostreicultura tem se destacado como uma atividade de grande potencial (Costa Neto, 2006; FAO, 2012). No Brasil, reconhece-se atualmente a ocorrência natural de duas espécies do gênero Crassostrea (Absher, 1989; Ignacio et al., 2000; Galvão et al., 2012). A espécie Crassostrea brasiliana (Lamarck, 1819) ocorre no infralitoral das regiões estuarinas e possui crescimento acentuado enquanto que Crassostrea rhizophorae (Guilding, 1828) ocorre predominantemente na região intermareal e apresenta menores taxas de crescimento quando comparada com C. brasiliana (Christo \& Absher, 2008). Os adultos de ambas as espécies são sésseis, caracterizados por apresentarem grande plasticidade na morfologia da concha, dependendo do substrato onde estão fixadas (Absher, 1989). Além destas duas espécies nativas, há no litoral brasileiro a presença da ostra japonesa Crassostrea gigas (Thumberg, 1793), em bancos naturais do litoral catarinense (Melo et al., 2010) e a presença de uma quarta espécie de ostra do gênero Crassostrea (Galvão et al., 2012, Amaral \& Simone, 2014).

As espécies de ostras do gênero Crassostrea possuem como características gônadas esbranquiça- 
das que envolvem e recobrem totalmente o tubo digestivo em indivíduos sexualmente maduros (Nascimento \& Lunetta, 1978).Possuem desenvolvimento larval planctotrófico e ausência de dimorfismo sexual externo (Andrews, 1979). O rápido crescimento e reestruturação gonadal das ostras destas espécies estão relacionados principalmente à quantidade e qualidade do fitoplâncton filtrado (Andrews, 1979). O suprimento e composição de alimento podem afetar a capacidade de crescimento dos organismos (Velez, 1991) e a transferência de reservas nutricionais da glândula digestiva para as gônadas, sendo estas posteriormente utilizadas nos processos de gametogênese (Galvão et al., 2000; Orban et al., 2004). A identificação das microalgas presentes no trato digestivo de ostras nativas aliadas a valores elevados nos índices fisiológicos de bivalves podem indicar espécies ou gêneros de algas nativas com potencial a ser utilizados na malacocultura brasileira. Além disso, a análise das espécies de algas presente na glândula digestiva de bivalves pode ser uma ferramenta adicional a ser empregada em programas de monitoramento ambiental de algas nocivas em regiões de cultivo. Portanto, este trabalho teve como objetivos descrever características fisiológicas (índice de rendimento da carne e estágio de maturação das gônadas) e avaliar o tamanho e os principais táxons de microalgas ingeridas por adultos de ostra Crassostrea brasiliana comercializadas no Mercado Municipal de Paranaguá, Paraná - Brasil.

\section{MATERIAIS E METODOS}

\section{Área de estudo}

O litoral do Paraná, localizado no sul do Brasil, estende-se desde a Vila de Ararapira ao

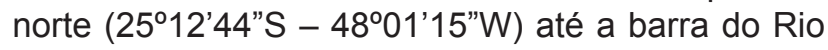
Saí-Guaçu, ao sul (2558'38”S - 48³5'26”W). O Complexo Estuarino de Paranaguá (CEP) é o maior sistema estuarino do estado do Paraná. Na face leste, o CEP sofre influência do oceano através das barras Norte (Canal Sueste) e Sueste (Canal da Galheta) e é circundado por bacias hidrográficas com cerca de $3.361 \mathrm{~km}^{2}$ de área (Maack, 1981) (Figura 1). Em relação ao uso e exploração de ostras nativas identificaram-se dezesseis locais de cultivo associados a comunidades de pescadores artesanais (Absher et al., 2007; Noernberg et al., 2008), distribuídos predominantemente na região norte do CEP (Figura 1). Estas comunidades efetuam a extração de ostras, associadas a atividades de engorda e crescimento de organismos em sistema de cultivo (Absher et al., 2007;

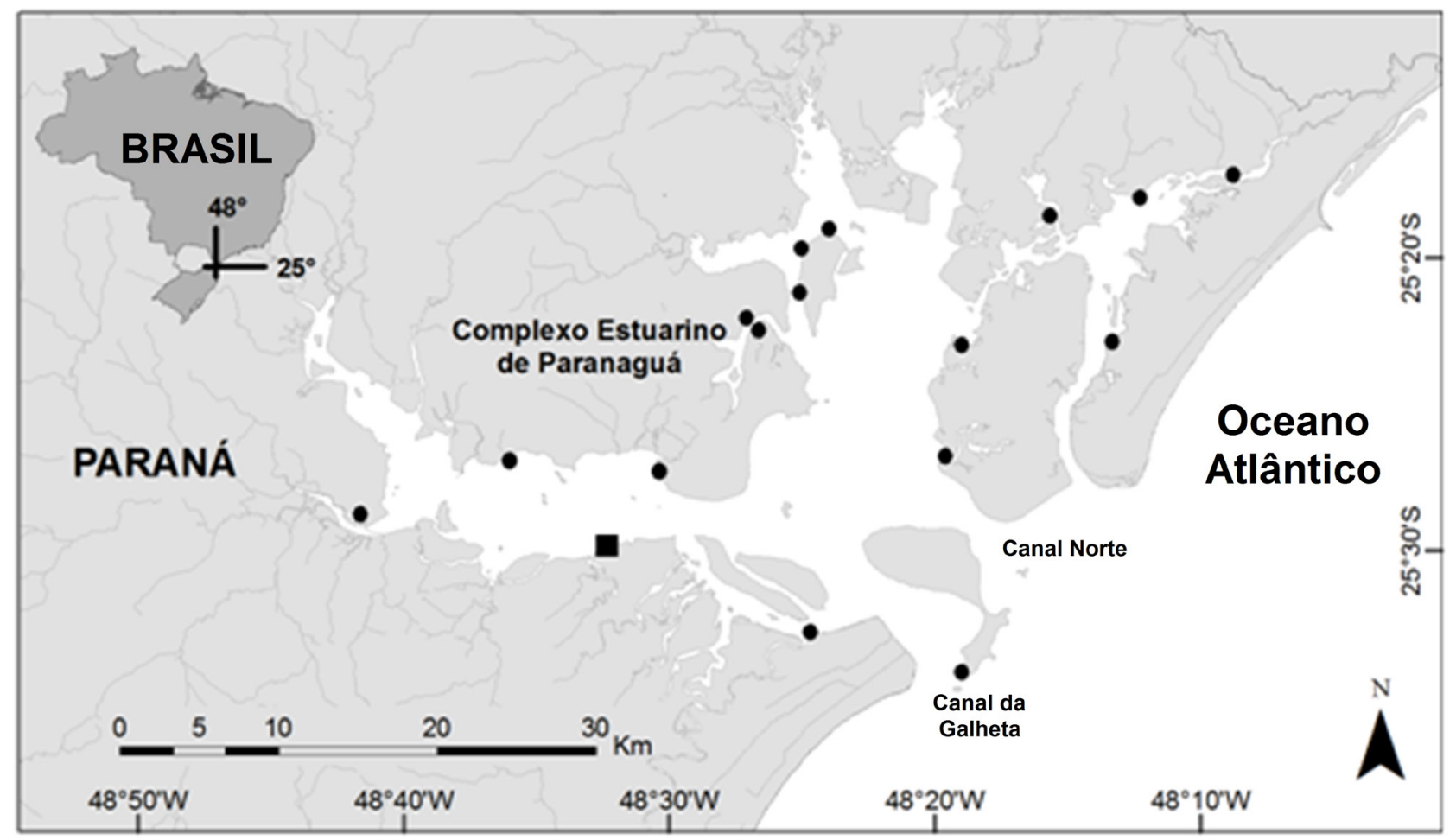

Figura 1 - Caracterização de regiões com cultivos de moluscos no Complexo Estuarino de Paranaguá $(\bullet)$ e ponto de escoamento ( $\mathbf{\square})$. Adaptado de Absher et al. (2007) e Noernberg et al. (2008). 
Noernberg et al., 2008). Esta produção é predominantemente escoada para as cidades de Paranaguá e Curitiba.

\section{Processamento das amostras}

As ostras foram adquiridas no Mercado Municipal de Paranaguá (ponto de escoamento) no período entre março de 2007 a março de 2008. Mensalmente, foram obtidos 30 indivíduos, que foram levados para o laboratório e mensurados em relação à altura (A - umbo a região oposta) e comprimento (Co - região anterior a região posterior) da concha. Ostras com altura abaixo de $20 \mathrm{~mm}$ não foram considerados por serem indivíduos jovens (Nascimento, 1991). As ostras foram pesadas ( $\mathrm{Pb}$ - peso bruto) e, após a retirada da concha, foi realizado o exame macroscópico das gônadas para verificar o estágio de repleção gonadal (Christo \& Absher, 2006). Em seguida, as partes moles foram pesadas para a obtenção do peso úmido da carne (Pca). Posteriormente, o trato digestivo (do esôfago até o intestino) foi retirado e fixado em solução transeau (solução 6:3:1) para posterior análise em microscópio óptico das microalgas ingeridas.

O rendimento da carne da ostra $(R)$ representa a porcentagem de carne (Pca) em relação ao peso bruto $(\mathrm{Pb})$ do individuo e foi calculado através da seguinte fórmula (Absher \& Christo, 1993):

$$
R=\frac{P c a}{P b} \times 100
$$

Foram avaliadas as microalgas encontradas no trato digestivo das ostras ( $n=3$ por mês) durante dois períodos (abril a junho de 2007 e dezembro de 2007 a março de 2008) em microscópio óptico. As microalgas do trato digestivo das ostras foram identificadas ao nível de gênero, quantificadas e classificadas em relação ao grupo taxonômico (diatomáceas ou dinoflagelados), segundo Tomas (1997). Posteriormente, as microalgas foram avaliadas quanto à morfologia (no caso das diatomáceas: penadas e cêntricas) e biometria, obtendo-se: largura (I), comprimento (c) para diatomáceas penadas; ou diâmetro (d) para as diatomáceas cêntricas e dinoflagelados.

\section{Tratamento dos dados}

A frequência relativa foi utilizada para descrever o estágio gonadal e a ocorrência das microalgas encontradas na glândula digestiva das ostras adultas a cada período amostral. Após a avaliação da normalidade e homocedasticidade dos dados, uma análise de Variância uni-fatorial foi empregada para mostrar as diferença $(\alpha=0,05)$ entre as médias de rendimento da carne (variável dependente) em relação às estações do ano (variável independente).

\section{RESULTADOS}

Durante este trabalho, foi analisado um total de 390 indivíduos e obtidos os valores médios de 82,87 $\mathrm{mm}( \pm 11,43)$ para a altura e de $58,41 \mathrm{~mm}( \pm 6,94)$ para o comprimento de concha. Para a biomassa, foram

Tabela 1 - Caracterização das médias da biometria da concha ( $\mathrm{A}$ - altura; Co - comprimento), biomassa (Pb - peso bruto; Pca - peso úmido da carne), índice de rendimento da carne (R) e estágio da maturação das gônadas (ERG) de adultos de Crassostrea brasiliana no Complexo Estuarino de Paranaguá. n- número de ostras adultas; \% - frequências relativas de repleção das gônadas; $V$ - vazia; PV parcialmente vazia; $\mathrm{PC}$ - parcialmente cheia; $\mathrm{C}$ - cheia.

\begin{tabular}{|c|c|c|c|c|c|c|c|c|c|c|c|}
\hline \multirow{2}{*}{ Estações } & \multirow{2}{*}{ Coletas } & \multirow{2}{*}{$n$} & \multicolumn{2}{|c|}{ Biometria } & \multicolumn{2}{|c|}{ Biomassa } & \multirow{2}{*}{$\mathbf{R}$} & \multicolumn{4}{|c|}{ ERG } \\
\hline & & & $A(\mathrm{~mm})$ & $\mathrm{Co}(\mathrm{mm})$ & $\mathrm{Pb}(\mathrm{g})$ & $\mathrm{PCa}(\mathrm{g})$ & & $\% \mathrm{~V}$ & $\% \mathrm{PV}$ & $\% \mathrm{PC}$ & $\% \mathrm{C}$ \\
\hline \multirow{3}{*}{ Outono } & $\mathrm{mar} / 07$ & 30 & 77,00 & 67,14 & 68,00 & 8,00 & 11,76 & 10,00 & 0,00 & 60,00 & 30,00 \\
\hline & $\mathrm{abr} / 07$ & 30 & 102,20 & 62,00 & 103,90 & 9,90 & 9,50 & 70,00 & 30,00 & 0,00 & 0,00 \\
\hline & mai/07 & 30 & 93,80 & 60,10 & 99,50 & 7,80 & 7,83 & 33,00 & 43,00 & 20,00 & 4,00 \\
\hline \multirow{3}{*}{ Inverno } & jun/07 & 30 & 77,00 & 57,00 & 64,60 & 6,30 & 9,70 & 55,00 & 39,00 & 3,00 & 3,00 \\
\hline & $\mathrm{jul} / 07$ & 30 & 78,70 & 54,00 & 68,80 & 8,80 & 12,79 & 12,00 & 0,00 & 22,00 & 66,00 \\
\hline & ago/07 & 30 & 108,00 & 62,00 & 73,40 & 4,90 & 6,67 & & & & \\
\hline \multirow{3}{*}{ Primavera } & set/07 & 30 & 72,60 & 71,00 & 79,70 & 7,62 & 10,53 & 20,00 & 24,00 & 50,00 & 6,00 \\
\hline & out/07 & 30 & 86,40 & 63,10 & 74,00 & 7,40 & 10,00 & 12,00 & 20,00 & 53,00 & 15,00 \\
\hline & nov/07 & 30 & 78,40 & 55,30 & 59,40 & 7,40 & 12,45 & 27,00 & 20,00 & 40,00 & 13,00 \\
\hline \multirow{3}{*}{ Verão } & $\operatorname{dez} / 07$ & 30 & 75,80 & 52,00 & 61,40 & 7,50 & 12,21 & 0,00 & 21,00 & 52,00 & 27,00 \\
\hline & $\mathrm{jan} / 08$ & 30 & 73,00 & 47,80 & 65,00 & 6,50 & 10,00 & 0,00 & 33,00 & 50,00 & 17,00 \\
\hline & fev/08 & 30 & 75,20 & 48,10 & 55,00 & 5,30 & 9,60 & 0,00 & 36,60 & 56,70 & 6,70 \\
\hline Outono & $\mathrm{mar} / 08$ & 30 & 79,30 & 59,80 & 69,80 & 6,80 & 9,74 & 6,00 & 60,00 & 30,00 & 4,00 \\
\hline
\end{tabular}


observados valores médios de $72,50 \mathrm{~g}( \pm 14,52)$ para o peso bruto $(\mathrm{Pb})$ e de 7,24 gramas $( \pm 1,34)$ para 0 peso das carnes das ostras (Tabela 1).

Em relação ao rendimento da carne $(R)$, os resultados dos meses amostrados indicaram os maiores valores das médias nos meses de julho
(12,79\%), novembro (12,45\%) e dezembro de 2007 (12,21\%); enquanto os menores valores médios foram observados nos meses de maio $(7,83 \%)$ e agosto de 2007 (6,67\%), não sendo verificadas diferenças significativas $(p>0,05)$ durante as estações do ano (Figura 2; Tabela 1).

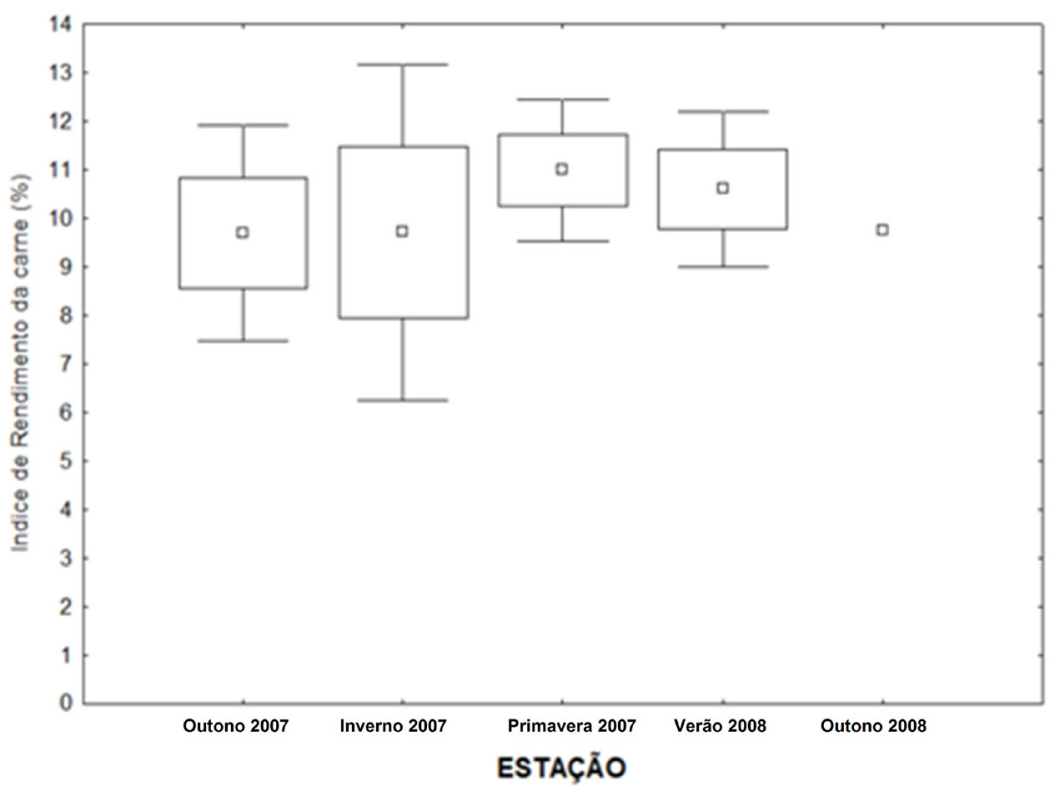

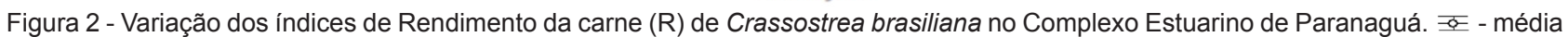
e amplitude de R. Estações do ano conforme definido na Tabela 1.

As análises macroscópicas dos estágios de maturação gonadal, indicaram um maior número de indivíduos com gônadas cheia (C) e parcialmente cheia (PC) no período de primavera e verão, indicando condição de maturação sexual em períodos de maiores temperaturas da água do mar. Porém, no mês de julho de $2007,66 \%$ dos indivíduos apresentaram gônadas $\mathrm{C}$, sendo este o maior índice obtido entre os meses investigados. Em agosto de 2007 não foi avaliada a maturação gonadal das ostras, pois no momento da compra observou-se a desova dos organismos (Figura 3; Tabela 2). A proporção sexual registrada em indivíduos com tecido gonadal (cheio, parcialmente cheio e parcialmente vazio) indicou um número de fêmeas $(F)$ superior ao de machos $(M)$, na proporção de $2 \mathrm{~F}: 1 \mathrm{M}$ (Tabela 2).

Tabela 2 - Caracterização das microalgas ingeridas por ostras adultas da espécie Crassostrea brasiliana no Complexo Estuarino de Paranaguá. $\mathrm{n}$ - número de microalgas encontradas nas glândulas digestivas; \% - frequências relativas de microalgas; $\mathrm{d}$ - médias do diâmetro dos dinoflagelados e diatomáceas cêntricas; c - médias do comprimento das microalgas diatomáceas penadas; l- médias da largura das microalgas diatomáceas penadas; DP - desvio padrão.

\begin{tabular}{|c|c|c|c|c|c|c|c|c|c|c|c|c|c|c|c|c|c|}
\hline \multirow{3}{*}{ Estaçöes } & \multirow{3}{*}{ Coletas } & \multirow{3}{*}{ Ostras } & \multicolumn{10}{|c|}{ Diatomáceas } & \multirow{2}{*}{\multicolumn{4}{|c|}{ Dinoflagelados }} & \multirow{3}{*}{$\mathbf{n}$} \\
\hline & & & \multicolumn{4}{|c|}{ Cêntrica $(\mu \mathrm{m})$} & \multicolumn{6}{|c|}{ Penada $(\mu \mathrm{m})$} & & & & & \\
\hline & & & $\mathbf{n}$ & $\%$ & d & $( \pm \mathrm{DP})$ & $\mathbf{n}$ & $\%$ & c & $( \pm \mathrm{DP})$ & I & $( \pm \mathrm{DP})$ & $\mathbf{n}$ & $\%$ & d & $( \pm \mathrm{DP})$ & \\
\hline \multirow{2}{*}{ Outono } & $\mathrm{abr} / 07$ & 3 & 5 & 41,67 & 58,60 & 27,40 & 6 & 50,00 & 75,00 & 19,30 & 14,33 & 7,74 & 1 & 8,33 & 41,00 & 0,00 & 12 \\
\hline & $\mathrm{mai} / 07$ & 3 & 14 & 45,16 & 62,00 & 29,53 & 15 & 48,39 & 75,47 & 68,41 & 16,60 & 11,27 & 2 & 6,45 & 41,00 & 0,00 & 31 \\
\hline \multirow[t]{2}{*}{ Inverno } & jun $/ 07$ & 3 & 7 & 46,67 & 80,00 & 33,67 & 8 & 53,33 & 74,25 & 20,25 & 19,50 & 12,59 & 0 & 0,00 & 0,00 & 0,00 & 15 \\
\hline & $\mathrm{dez} / 07$ & 1 & 0 & 0,00 & 0,00 & 0,00 & 7 & 53,85 & 59,43 & 19,65 & 16,00 & 8,94 & 6 & 46,15 & 30,00 & 12,07 & 13 \\
\hline \multirow[t]{2}{*}{ Verão } & $\mathrm{jan} / 08$ & 3 & 34 & 21,38 & 25,76 & 14,97 & 80 & 50,31 & 83,45 & 44,25 & 11,75 & 5,81 & 45 & 28,30 & 28,53 & 22,96 & 159 \\
\hline & $\mathrm{fev} / 08$ & 3 & 35 & 35,35 & 29,17 & 18,07 & 64 & 64,65 & 80,73 & 48,07 & 9,47 & 4,23 & 0 & 0,00 & 0,00 & 0,00 & 99 \\
\hline Outono & $\mathrm{mar} / 08$ & 1 & 30 & 56,60 & 27,10 & 11,64 & 6 & 11,32 & 49,33 & 25,38 & 14,67 & 7,00 & 17 & 32,08 & 30,12 & 11,84 & 53 \\
\hline \multicolumn{2}{|c|}{ Somatória } & 8 & 125 & - & - & - & 186 & - & - & - & - & - & 71 & - & - & - & 382 \\
\hline
\end{tabular}




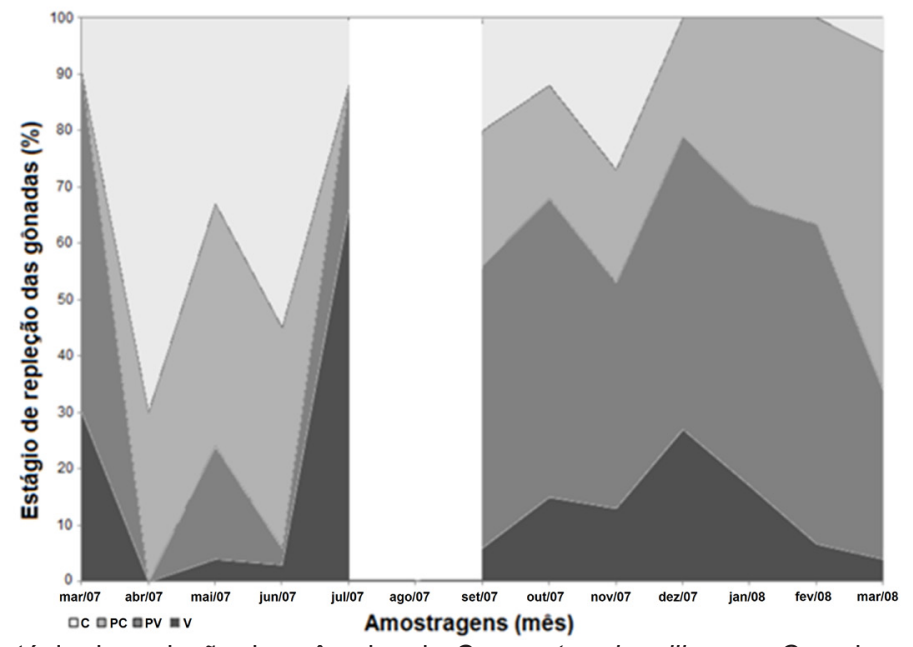

Figura 3 - Caracterização do estágio de repleção das gônadas de Crassostrea brasiliana no Complexo Estuarino de Paranaguá, classificado entre: (V) vazio; (PV) parcialmente vazio; (PC) parcialmente cheio e (C) cheio.

As análises biométricas das microalgas ingeridas indicaram células variando de 5 a $260 \mu \mathrm{m}$, com valores médios para diatomáceas penadas de $79,20 \mu \mathrm{m}( \pm 45,69)$ de comprimento e $12,02 \mu \mathrm{m}$ $( \pm 7,01)$ de largura; $35,45 \mu \mathrm{m}( \pm 24,87)$ de diâmetro médio para diatomáceas cêntricas e 29,56 $\mu \mathrm{m}$ $( \pm 19,50)$ de diâmetro médio para os dinoflagelados (Tabela 2). Sendo que os gêneros observados foram: Diatomáceas - Gyrosigma; Cyclotella; Coscinodiscus;
Pleurosigma; Rhizosolenia; Navicula; Nitzschia; Opephora; Diploneis; Frustulia; Anomoeoneis; Chroococcus; Cocconeis; Coscinodiscus; Odontella e Thalassionema, que representaram $81,41 \%$ das microalgas ingeridas; Dinoflagelados - Noctiluca, Ceratium e Prorocentrum, que representaram 18,59\% das algas encontradas no trato digestivo de ostras adultas (Figura 4; Tabela 2).
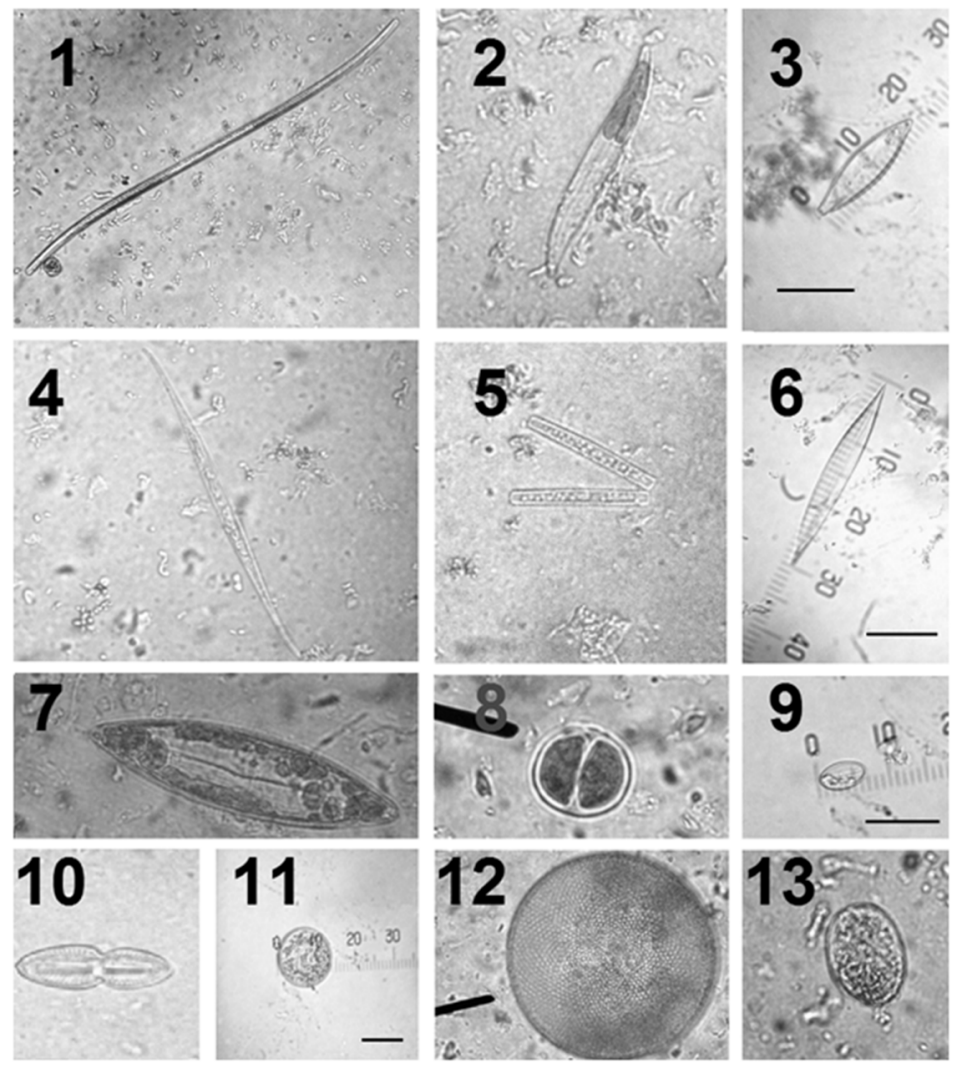

Figura 4 - Fotomicrográfias dos gêneros de microalgas encontrados no trato digestivo de ostras adultas da espécie Crassostrea brasiliana no Complexo Estuarino de Paranaguá. 1)Nitzchia; 2)Gyrosigma; 3)Navicula; 4)Pleurosigma; 5)Thalassionema; 6)Frustulia; 7)Anomoeoneis; 8)Chroococcus; 9)Cocconeis; 10)Diploneis; 11)Cyclotella; 12)Coscinodiscus; 13)Prorocentrum. Escala:40 $\mu \mathrm{m}$. 


\section{DISCUSSÃO}

Inúmeros estudos relacionados ao ciclo reprodutivo de espécies de ostras do gênero Crassostrea indicaram que a maturação gonadal está relacionada principalmente à variação de temperatura. Estes estudos podem ser constatados com Crassostrea gigas (Thunberg, 1793) (Ruiz et al., 1992; Kang et al., 2000; Ren et al., 2003); Crassostrea gasar Adanson (1757) (Diadhiou \& Le Pennec, 2000) e com Crassostrea virginica (Gmelin, 1791) (Rainer \& Mann, 1992; Brousseau, 1995). No presente estudo, embora a maior porcentagem de indivíduos com gônadas cheias e/ou parcialmente cheias também tenha sido observada em períodos de águas mais quentes (março e dezembro de 2007), os níveis mais elevados de maturação gonadal foram alcançados em um único mês de águas frias, julho de 2007 , quando $66 \%$ dos indivíduos estavam com as gônadas cheias. Isso corrobora o fato de que as ostras do litoral paranaense apresentam uma reprodução contínua ao longo do ano, como observado por Absher (1989) e Boehs-Silva \& Absher (1996) na Baía de Paranaguá e por Christo (2006) na Baía de Guaratuba.

Galvão et al. (2000), constataram que o rendimento da carne é maior nos indivíduos em estágio mais avançados de maturação gonadal. Essa tendência pode ser observada no presente estudo, através das maiores médias do $\mathrm{R}$ em março $(11,76 \%)$, julho $(12,79 \%)$ e dezembro $(12,21 \%)$ de 2007 , quando uma grande parcela da população apresentou gônadas cheias. Sendo assim, os valores do rendimento da carne e da repleção das gônadas permitem uma associação indireta das condições nutricionais e reprodutivas de Crassostrea brasiliana comercializadas no Mercado Municipal de Paranaguá. A mesma associação foi observada por Ruiz et al. (1992) em estudos realizados com Crassostrea gigas, que relacionou o ciclo gametogênico a condições ambientais, mostrando que a maturação gonadal está relacionada com a temperatura e níveis de clorofila. Estas características ambientais podem afetar o estado nutricional de ostras, referente ao conteúdo total de proteínas, lipídeos e glicogênio, fatores estes importantes na condição fisiológica dos organismos associada à reprodução (Kang et al., 2000; Ren et al., 2003). No entanto, estudos reprodutivos em entrepostos de venda de moluscos não são os ideais, visto que as ostras comercializadas no Mercado Municipal de Paranaguá são mantidas parcial ou integralmente submersas em água com grande variação de temperatura e salinidade. Estas oscilações podem estimular a desova das ostras (Andrews, 1979), alterando as condições fisiológicas dos indivíduos (índices aqui avaliados). Em decorrência disto, os organismos coletados em agosto de 2007 não foram avaliados em relação à maturação gonadal, pois no momento da compra observou-se a desova dos organismos. Com esta desova pode-se afirmar que no mês de agosto de 2007 há atividade reprodutiva de ostras do CEP, corroborando novamente a constatação de que as ostras do litoral paranaense apresentam uma reprodução contínua ao longo do ano (Absher, 1989; Boehs-Silva \& Absher,1996; Christo, 2006).

Além disto, o método de armazenamento utilizado pelos comerciantes do Mercado Municipal de Paranaguá não é fisiologicamente ideal para a venda das ostras, visto que no mês de agosto de 2007 há uma diminuição do $\mathrm{R}$ comparado com os demais meses. Uma alternativa para sanar o problema seria a conservação das ostras em ambientes refrigerados.

Costa (1985) relatou que ostras do gênero Crassostrea podem ingerir partículas com diâmetro inferior a $10 \mu \mathrm{m}$. Estudos realizados por Spittler et al. (1989) demonstraram que indivíduos desse gênero podem ingerir partículas de vários tamanhos, até um limite máximo de aproximadamente $98 \mu \mathrm{m}$. Uma revisão efetuada por Ward et al. (2004), indicou que bivalves suspensívoros possuem uma plasticidade morfológica nas estruturas das lamelibrânquias em regiões de alta turbidez, podendo resultar em alterações funcionais que propiciam uma maior eficiência de captura e seleção das partículas em ambientes com diferentes concentrações de seston. As microalgas encontradas na glândula digestiva revelaram que a espécie Crassostrea brasiliana pode se alimentar de microalgas entre 5 e $260 \mu \mathrm{m}$ de comprimento, com predominância de microalgas no intervalo de 10 a 98 $\mu \mathrm{m}$, e com menor predomínio de colônias de microalgas em relação a células isoladas. Não foi possível uma avaliação mais aprofundada das características das colônias de microalgas (tais como o número de células e comprimento da colônia), decorrentes da ação enzimática do suco gástrico presentes no trato digestivo das ostras e da quebra mecânica promovida pelo estilete cristalino.

Como a espécie de ostra investigada é um organismo epibionte e tem sua ocorrência predominante em regiões de infralitoral associado a canais de marés, a ressuspensão de microalgas bênticas associada a tais ambientes pode possibilitar uma melhor nutrição às ostras. De fato, Brandini \& Thamm (1994) descreveram a ocorrência de espécies bentônicas dos gêneros de Navicula, Cocconeis Ehrenberg, 1837 e Diploneis nas amostragens de fitoplâncton do CEP, decorrentes provavelmente da ressuspensão do fundo na maré enchente e alterações na pluviometria local. Dispor de uma dieta diversificada, composta de microalgas planctônicas e bênticas, é possivelmente uma característica essencial para alguns estágios de vida 
da espécie estudada, visto que larvas pedivéliger da espécie Crassostrea brasiliana possuem uma maior predominância de assentamento na região do infralitoral (Absher, 1989; Christo, 2006). Estudos realizados com o padrão alimentar de larvas de $C$. virginica no ambiente natural indicaram que a qualidade da dieta não depende somente do tamanho das partículas, mas também da fase de crescimento e composição química das microalgas (Baldwin, 1995; Baldwin \& Newell, 1995). Rico-Villa et al. (2006), indicaram um maior desenvolvimento das larvas de $C$. gigas quando utilizadas dietas mistas da diatomácea Chaetoceros calcitrans forma pumilum e outra microalga flagelada (Pavlova lutheri e/ou Isochrysis affinis galbana). Procopiak et al., (2006) descreveram para as águas do CEP a ocorrência de 575 táxons infragenéricos de microalgas, distribuídos dentre 152 gêneros, tendo alguns destes gêneros espécies potencialmente tóxicas, como por exemplo o gênero Pseudo-nitzschia H. Peragallo, 1900, cujas espécies são produtoras do ácido domóico causador do envenenamento Amnésico por Consumo de Moluscos (ASP) e a espécie Dinophysis acuminata Claparède \& Lachmann, 1859 produtora de toxinas diarréicas (DSP) (Procopiak et al., 2006; Mafra-Junior et al. 2006). Apesar destas espécies não terem sido encontradas no presente estudo, foram identificadas no trato digestivo de ostras adultas células pertencentes ao gênero Prorocentrum, que possuem algumas espécies bênticas com potencial na produção de toxinas, como P. lima, por exemplo (Mafra-Junior et al., 2006), e outras espécies com potencial para uso como fonte alimentar de invertebrados marinhos (Mafra-Junior, comunicação pessoal). Embora as microalgas não tenham sido identificadas em nível de espécie no presente estudo, impossibilitando qualquer afirmação sobre a ingestão de espécies potencialmente tóxicas de Prorocentrum por C. brasiliana. A presença da espécie de microalgas com potencial de produção de toxinas, como Prorocentrum minimum no CEP (Mafra-Junior et al., 2006) e a identificação de ingestão de células pertencentes ao gênero Prorocentrum, demonstra a necessidade de programas de monitoramento quanto a presença de algas tóxicass na região. Estudos experimentais efetuados com bivalves (Argopecten irradians, Crassostrea virginica, Mercenaria mercenaria, Mya arenaria e Mytilus edulis) avaliando a taxa de filtração de três espécies de algas potencialmente produtoras de toxinas ( $P$. minimum, Alexandrium fundyense e Heterosigma akashiwo), indicaram um fechamento parcial das valvas de C. virginica e a presença de $P$. minimum nas fezes e peseudofezes (Hégaret et al., 2007).

Através deste estudo, foi possível constatar a diversidade de microalgas que ostras adultas podem ingerir, desde gêneros autotróficos planctônicos
(Coscinodiscus) e bênticos (Diploneis, Navicula) até heterotróficos (Noctiluca). Brandini \& Thamm (1994) descreveram a dominância de algas não nocivas (diatomáceas - 90\%) no CEP, tendo uma maior ocorrência de Skeletonema costatum Cleve, 1873 e dos gêneros Coscinodiscus e Asterionella Hassall, 1850 para as de forma cêntricas, e da espécie Thalassionema nitzschioides Grunow \& Mereschkowsky, 1902 e do gênero Nitzschia para as formas penadas. Estes mesmos autores relatam uma relação positiva do aumento da dominância de diatomáceas com o regime pluviométrico. A dominância de diatomáceas $(81,41 \%)$ também foi constatada nas microalgas ingeridas por ostras no período deste estudo no CEP. Estudos experimentais com Crassotrea gigas indicaram uma predominância da ingestão de diatomáceas (Benninger et al., 2008a; b).

Os resultados obtidos neste trabalho permitem concluir que há uma reprodução contínua de C. brasiliana ao longo do ano na região de estudo, com maior atividade reprodutiva entre dezembro de 2007 a fevereiro de 2008. Além disso, o tamanho das microalgas ingeridas por ostras adultas pode ultrapassar $100 \mu \mathrm{m}$, tendo estas uma grande variação de tamanho (5 a $260 \mu \mathrm{m})$.

\section{REFERÊNCIAS BIBLIOGRÁFICAS}

Absher, T. M., 1989. Populações naturais de ostras do gênero Crassostrea do litoral do Paraná - Desenvolvimento larval, recrutamento e crescimento. Tese de doutorado. Universidade de São Paulo, Instituto Oceanográfico, 185p.

Absher, T. M. \& Christo, S. W. 1993. Índice de Condição de ostras da região entre-marés da Baía de Paranaguá, Paraná. Arq. Biol. Tecnol., 36(2): 253-261.

Absher, T. M.; Caldeira, G. A.; Elbers, K. L. \& Monteiro, L. C. 2007. Caracterização dos parques de cultivos de ostras do litoral do Paraná: aspectos técnicoprodutivos e socioeconômicos. In: Barroso, G. F.; Goersch, L. H. S. \& Cavalli, R. O. 2007. Sistemas de cultivos aquícolas na zona costeria do Brasil: recursos, tecnologias, aspectos ambientais e sócio-econômicos. Rio de Janeiro: Museu Nacional, 316p.

Amaral, V. S. D., \& Simone, L. R. L. 2014. Revision of genus Crassostrea (Bivalvia: Ostreidae) of Brazil. Journal of the Marine Biological Association of the United Kingdom, 94(04): 811-836.

Andrews, J. D. 1979. Pelecypoda: Ostreidae. In: GIESE, A. C. \& PIERSE, J. S. ed Reproduction of Marine Invertebrates. New York, Academic Press. p. 293-341. 
Baldwin, B. S. 1995. Selective particle ingestion by oyster larvae (Crassostrea virginica) feeding on natural seston and cultured algae. Marine Biology, 123(1): 95-107.

Baldwin, B. S. \& Newell, R. I. 1995. Feeding rate responses of oyster larvae (Crassostrea virginica) to seston quantity and composition. Journal of experimental marine biology and ecology, 189(1): 77-91.

Beninger, P. G.; Valdizan, A.; Cognie, B.; Guiheneuf, F., \& Decottignies, P. 2008a. Wanted: alive and not dead: functioning diatom status is a quality cue for the suspension-feeder Crassostrea gigas. Journal of plankton research, 30(6): 689-697.

Beninger, P. G.; Valdizan, A.; Decottignies, P., \& Cognie, B. 2008b. Impact of seston characteristics on qualitative particle selection sites and efficiencies in the pseudolamellibranch bivalve Crassostrea gigas. Journal of Experimental Marine Biology and Ecology, 360(1): 9-14.

Boehs-Silva, G. \& Absher, T. M. 1996. Variação temporal de larvas de ostras do gênero Crassostrea SACCO, 1897 (Ostreoida:Ostreidae) na Baía de Paranaguá, Paraná. Arq. Biol. Tecnol., 39(4): 903-910.

Brandini, F. P. \& Thamm, C. A. C. 1994. Variações diárias e sazonais do fitoplâncton e parâmetros ambientais na baía de Paranaguá. Nerítica, 8(1-2), Curítiba, p. 55-72, Editora UFPR.

Brousseau, D. J. 1995. Gametogenesis and spawning interdital oysters (Crassostrea virginica) from Western Long Island Sound. J. Shellfish Res., 14(2): 483-487.

Christo, S. W. 2006. Biologia reprodutiva e ecologia de ostras do gênero Crassostrea (SACCO, 1987) na Baía de Guaratuba (Paraná - Brasil): um subsidio ao cultivo. Tese (Doutorado em Zoologia) - Universidade Federal do Paraná, 137 p.

Christo, S. W. \& Absher, T. M. 2006. Reproductive period of Crassostrea rhizophorae (GUILDING, 1828) and Crassostrea brasiliana (Lamark, 1819) (Bivalvia: ostreidae) in Guaratuba bay, Paraná, Brazil. Journal of Coastal Research, SI 39, 1215 - 1218. Itajaí, SC, Brazil.

Christo, S. W. \& Absher, T. M. 2008. Crescimento da prodissoconcha de ostras do gênero Crassostrea SACCO, 1897 (Bivalvae:Ostreidae). B. Inst. Pesca, 34(1): $71-77$.

Costa, P. F. 1985. CAP.VI: PARTE B: Biologia e tecnologia para o cultivo. In: MINISTÉRIOS DA MARINHA; INSTITUTO NACIONAL DE ESTUDOS DO MAR; BRASIL. Manual de Maricultura. Rio de Janeiro, Impressão IPqM. p. VI,1B - VI,40B.

Costa-Neto, E. M. 2006. Os moluscos na zooterapia: medicina tradicional e importância clínico- farmacológica. Biotemas, 19(3): 71-78, setembro de 2006, ISSN 0103 - 1643.

Diadhiou, H. D. \& Le Pennec, M. 2000. Reproduction of the oyters Crassostrea gasar (mollusc, bivalve) in Southern Casamance (Senegal). Mar. Life 10(12): 19-25.

FAO - Food and agriculture organization of the united nations. 2012. The State of World Fisheries and Aquaculture (SOFIA) Roma. Departamento de Pesca e Aquicultura da FAO. Disponível em:<http:// www.fao.org/docrep/016/i2 727e/i2727e00.htm>. Acesso em: 03 fevereiro 2013.

FAO - Organización de las Naciones Unidas para la Alimentación y la Agricultura. 2014. Global Aquaculture Production Volume and Value Statistics Database Updated to 2012. Roma, FAO. 223p.

Galvão, M. S. N.; Pereira, O. M.; Machado, I. C. \& Henrique, M. B. 2000. Aspectos reprodutivos da ostra Crassostrea brasiliana de manguezais do estuário de Cananéia, SP $\left(25^{\circ} \mathrm{S} ; 48^{\circ} \mathrm{W}\right)$. B. Inst. Pesca, 26(2):147-162.

Galvão, M. S.; Pereira, O. M. \& Hilsdorf, A. W. 2013. Molecular identification and distribution of mangrove oysters (Crassostrea) in an estuarine ecosystem in Southeast Brazil: implications for aquaculture and fisheries management. Aquaculture Research, 44(10): 1589-1601.

Hégaret, H.; Wikfors, G. H. \& Shumway, S. E. 2007. Diverse feeding responses of five species of bivalve mollusc when exposed to three species of harmful algae. Journal of Shellfish Research, 26(2): 549-559.

Ignacio, B. L.; Absher T. M.; Lazoski, C. \& Solé-Cava, A. M. 2000. Genetic evidence of the presence of two species of Crassostrea (Bivalvia: Ostreidae) on the coast of Brazil. Marine Biology, 136: 987-991.

Kang, C. K.; Park, M. S.; Lee, P. Y.; Choi, W. J. \& Lee, W. C. 2000. Seasonal variation in condition, reproductive activity and biochemical composition of the acific oyster Crassostrea gigas, in suspended culture in two coastal bays of Korea. J. Shellfish Res., 19(3): 771-778.

Lenz T. \& Boehs G. 2011. Ciclo reproductivo del ostión de manglar Crassostrea rhizophorae (Bivalvia: Ostreidae) en la Bahía de Camamu, Bahia, Brasil. Rev. Biol. Trop. 59(1): 137-149.

Maack, R. 1981. Geografia física do Estado do Paraná. Curitiba, J. Olympio/Secretaria da Cultura e Esporte do Estado do Paraná. 450p.

Mafra Junior, L. L.; Fernandes, L. F. \& Proença, L. A. 2006. Harmful algas and toxins in Paranaguá bay, Brazil: bases for monitoring. Braz. Journ. of Oceanog., 54(1/2): 107-121. 
Mann, R. 1982. Ecology of coastal waters: a System Approach. University of California Press. Verkeley, CA. 322p.

Melo, C. M.; Silva, F. C.; Gomes, C. H. A.; Solé-Cava, A. M., \& Lazoski, C. 2010. Crassostrea gigas in natural oyster banks in southern Brazil.Biological Invasions, 12(3): 441-449.

Nascimento, I. A. 1978. Reprodução da ostra do mangue, Crassostrea rhizophorae (Guilding, 1828): um subsídio ao cultivo. Tese de doutorado, Instituto de Biociências, USP, 200p.

Nascimento, I. A. \& Lunetta, J. E. 1978. Ciclo sexual da ostra de mangue e sua importância para o cultivo. Bol. Fisiol. Animal, 2: 63-68, Universidade de São Paulo.

Nascimento, I. A. 1991. Crassostrea rhizophorae (Guilding) and C. brasiliana (Lamarck) in South and Central America. In: Menzel, W. (Ed.). Estuarine and marine bivalves mollusk culture. Boston, USA, CRC Press.

Nascimento, I. A. \& Pereira, S. A. 1980. Changes in the condition index for mangrove oysters (Crassostrea rhizophorae) from Todos os Santos Bay, Brazil. Aquaculture, 20: 9-15.

Noernberg, M. A.; Angelotti, R.; Caldeira, G. A. \& Ribeiro De Souza A. F. 2008. Determinação da sensibilidade do litoral paranaense à contaminação por óleo. Braz. J. Aquat. Sci. Technol., 12(2): 49-50.

Orban, E.; Lena, G.; Masci, M.; Nevigato, T.; Casini, I.; Caproli, R.; Gambelli, L. \& Pellizato, M. 2004. Growth, nutricional quality and safety of oysters (Crassostrea gigas) cultured in the Lagoon of Venice (Italy). J. Sci. Food. Agric., 84(14): 1929-1938.

Pillay, T. V. R. \& Kutty, M. N. 2005. Aquaculture: principles and practices. Disponível em: <http:// books.google.com.br/books>. Acesso em: 20 dezembro 2011.

Procopiak, L. K.; Fernandes, L. F. \& Moreira-Filho, H. 2006. Diatomáceas (Bacillariophyta) marinhas e estuarinas do Paraná Sul do Brasil: lista de espécies com ênfase em espécies nocivas. Biota Neotropica 6(3): 28.
Rainer, J. F. \& Mann, R. 1992. A comparasion of methods for calculating condition index in eastern oysters, Crassostrea virginica (Gmelin, 1791). J. Shellfish Res., 11 (1):55-58.

Ren, J. S.; Ross, A. H. \& Schiel, D. R. 2003. Functional descriptions of feeding and energetics of the Pacific oyster Crassotrea gigas in New Zealand. Mar. Ecol. Prog. Ser., 208:119-130.

Rico-Villa, B. Le Coz; J. R. Mingant, C. \& Robert, R. 2006. Influence of phytoplankton diet mixtures on microalgae consumption, larval development and settlement of the Pacific oyster Crassostrea gigas (Thunberg). Aquaculture, 256(1): 377-388.

Ruiz, C.; Abad, M.; Sedano, F.; Garcia-Martin, L. O. \& Sánchez López, J.L. 1992. Influence of seasonal environmental changes on the gamete production and biochemical composition of Crassostrea gigas (Thumberg) in suspended culture in EI Grove, Galicia, Spain. J. Exp. Mar. Biol. Ecol., 155:249-262.

Santos, J. J. 1978. Aspectos da ecologia e biologia da ostra Crassostrea rhizophorae (Guilding, 1828) na Baía de Todos os Santos. São Paulo, Tese de doutorado, Instituto de Biociências, USP, 166p.

Spittler, P.; Cruz, A. \& Rodriguez, J. 1989. La selección del tamaño de las partículas por el ostión Crassostrea rhizophorae. Revista de Investigaciones Marinas, 10(1):63.

Velezar. A. R. 1991. Reproduction and cultivation of the mangrove oyster Crassostrea rhizophorae in Venezuela. In: Oyster Culture Caribbean. Gary Newkirk \& Becky Field. Nova Scotia-Canadá: Dalhosie University Press, 292p.

Tomas, C. R. (Ed.). 1997. Identifying marine phytoplankton. London-UK: Academic press, 858p.

Ward, J. E. \& Shumway, S. E. 2004. Separating the grain from the chaff: particle selection in suspension-and deposit-feeding bivalves. Journal of Experimental Marine Biology and Ecology, 300(1): 83-130.
Submetido: Abril/2014 Revisado: Abril/2015 Aceito: Maio/2015 